\title{
Desempenho e exigências de energia e proteína de bovinos de corte em pasto suplementados
}

\author{
[Performance, energy and protein requirements of beef cattle grazing supplemented] \\ P.A.S. Machado, S.C. Valadares Filho, R.F.D. Valadares, M.F. Paulino, \\ P.V.R. Paulino, M.I. Marcondes
}

Universidade Federal de Viçosa - Viçosa, MG

\begin{abstract}
RESUMO
Avaliou-se o efeito dos níveis de suplementação sobre o desempenho, as características de carcaça, a composição corporal e as exigências de energia e proteína de bovinos de corte sob pastejo. A área experimental constituiu-se de cinco piquetes formados com Brachiaria decumbens. Utilizaram-se 22 bovinos não castrados, com peso corporal médio inicial de $320 \mathrm{~kg}$ e idade de 18 meses. Três animais foram abatidos ao início do experimento para servirem como referência. Dos 19 animais restantes, três foram designados ao grupo mantença (MT), os outros 16 foram distribuídos em quatro tratamentos: controle ou mistura mineral (MM), $1 \mathrm{~kg}, 2 \mathrm{~kg}$ e $3 \mathrm{~kg}$ de suplemento ao dia. Observou-se aumento linear no consumo de matéria seca (CMS), energia digestível (CED) e energia metabolizável (CEM); o consumo de nutrientes digestíveis totais (CNDT) foi máximo para o consumo de $2,88 \mathrm{~kg}$ de suplemento. O ganho médio diário (GMD) máximo, $0,91 \mathrm{~kg} / \mathrm{dia}$, foi observado para o consumo de suplemento de $2,69 \mathrm{~kg} / \mathrm{dia}$. Verificou-se aumento linear no peso corporal em jejum (PCJ), no peso de corpo vazio (PCVZ) e no peso da carcaça para os animais suplementados. Não foi observado efeito da suplementação sobre o rendimento da carcaça. Verificou-se aumento sobre a área de olho de lombo (AOL) e a espessura de gordura subcutânea (EGS), quando os animais não suplementados foram comparados com os suplementados. Não foi observado efeito para o comprimento da carcaça (CCA), nem para os rendimentos dos cortes comerciais. As exigências líquidas de energia e proteína apresentaram, respectivamente, aumento e redução com o aumento do PC dos animais. As exigências de energia líquida para mantença $(E L m)$ foram de $85 \mathrm{kcal} / \mathrm{PCVZ}^{0,75}$. As exigências de energia metabolizável para mantença foram estimadas em 130,08 kcal/PCVZ ${ }^{0,75}$. A suplementação de bovinos no período de transição águasseca aumenta o consumo de MS e energia, promovendo aumento do ganho de peso dos animais.
\end{abstract}

Palavras-chave: energia, exigências de mantença, proteína

\begin{abstract}
This experiment aimed to evaluate the performance, carcass characteristics, body composition, and energy and protein requirements of beef cattle under grazing conditions. The experimental area constituted of 5 paddocks with Brachiaria decumbens as forage source. Twenty two steers (Zebu) with mean body weight and ages of $320 \mathrm{~kg}$ and 18 months, respectively, were used. Three animals were slaughtered at the beginning of the experiment and used as standard. Of the nineteen remaining animals, three were designated for maintenance group and the others were randomly submitted to one of four treatments: mineral mixture (MM), 1, 2 or $3 \mathrm{~kg}$ of supplement daily. There was a linear increase in dry matter intake (DMI), digestible energy (DEI) and metabolizable energy (MEI), and total digestible nutrients intake (TDNI) was maximum consumption of $2.88 \mathrm{~kg}$ of supplement. The maximum average daily gain (ADG), 0.91kg/day, was observed for supplement intake of $2.69 \mathrm{~kg} /$ day. Linear increase was observed in shrunk body weight (SBW), EBW and carcass weight. There was no effect on the carcass allowance, however, it was observed on the ribeye area and back fat thickness. No effect was observed on
\end{abstract}

Recebido em 21 de março de 2011

Aceito em 6 de março de 2012

E-mail: polyana.silva@ufv.br 
carcass length and commercial cuts. The requirement of net energy (NE) and net protein (NP) increased and decreased as the animals $B W$ increased. The maintenance requirement for net $\left(N E_{m}\right)$ and metabolizable energy were $85 \mathrm{kcal} / E B \mathrm{~W}^{0.75}$ and $130 \mathrm{kcal} / \mathrm{EB} \mathrm{W}^{0.75}$. Supplementation of cattle in the period of transition between rainy and dry seasons increased the dry matter and energy intake, promoting an increase in animal weight gain.

Key words: energy, maintenance requirement, protein

\section{INTRODUÇÃO}

Para apresentarem ganho ótimo em pastagens, os animais precisam de nutrientes essenciais na proporção adequada para atender suas exigências nutricionais, portanto o suplemento deve ser considerado um complemento da dieta, para suprir os nutrientes deficientes na forragem disponível (Reis et al., 1997).

Segundo Barbosa et al. (2007) as quantidades a serem fornecidas dependem das metas a serem atingidas de acordo com o planejamento de ganho de peso proposto. Essa suplementação depende da qualidade e da disponibilidade de matéria seca do pasto.

Trabalhos desenvolvidos com o intuito de determinar as exigências nutricionais de bovinos a pasto no Brasil ainda são escassos, e os sistemas mais utilizados para a determinação das exigências são baseados em recomendações internacionais desenvolvidas em situações diferentes daquelas que representam a pecuária brasileira. O Brasil já dispõe de uma publicação nacional referente a essa área. A segunda edição do BR-CORTE (Valadares Filho et al., 2010) apresenta um banco de dados satisfatório para animais confinados, no entanto são necessários resultados de experimentos a pasto.
Este trabalho foi desenvolvido com o objetivo de avaliar o efeito da suplementação sobre o desempenho, as características de carcaça e a composição corporal, bem como determinar as exigências nutricionais de energia e proteína de bovinos em pastejo no período de transição águas-seca.

\section{MATERIAL E MÉTODOS}

Foram utilizados 22 animais Nelores, não castrados, com idade e peso médios iniciais, respectivamente, de 18 meses e $320 \mathrm{~kg}$.

Ao iniciar o experimento, foram abatidos três animais que serviram de referência no estudo da composição corporal inicial. Os 19 restantes foram distribuídos de forma aleatória entre $o$ grupo-mantença (MT) e os tratamentos mistura mineral (MM) ou controle e 1,2 e $3 \mathrm{~kg}$ de suplemento, conforme Tab. 1. Foram destinados ao grupo- mantença três animais, submetidos a pastejo restrito objetivando atender apenas as exigências de mantença. Os animais-mantença pastejaram durante duas horas diárias e, nas $22 \mathrm{~h}$ restantes, foram mantidos em piquete com 0,50ha, sem cobertura vegetal. Os tratamentos apresentaram quatro repetições cada. O período experimental teve duração total de 84 dias.

Tabela 1. Composição percentual dos suplementos, com base na matéria natural

\begin{tabular}{lcccc}
\hline \multirow{2}{*}{ Ingredientes (\%) } & \multicolumn{4}{c}{${\text { Tratamentos (suplemento, \% } \mathrm{PC}^{1} \text { ) }}$} \\
\cline { 2 - 5 } & $\mathrm{MM}^{3}$ & 0,33 & 0,66 & 1,00 \\
\hline Mistura mineral $^{2}$ 9\% P & 100 & 6,0 & 3,0 & 2,0 \\
Ureia/SA - 9:1 & - & 4,8 & 4,8 & 4,8 \\
Farelo de algodão 38\% PB & - & 30,0 & 30,0 & 30,0 \\
Grão de milho triturado & - & 59,2 & 62,2 & 63,2 \\
\hline
\end{tabular}

${ }^{1}$ Peso corporal. ${ }^{2}$ : fosfato bicálcico, $50 \%$; cloreto de sódio, 47,8\%; sulfato de zinco, 1,4\%; sulfato de cobre, 0,70; sulfato de cobalto, $0,05 \%$; e iodato de potássio, $0,05 \% .^{3}=$ mistura mineral.

A área experimental destinada aos animais foi constituída de cinco piquetes de 2,0ha cada, formados com Brachiaria decumbens Stapf., providos de bebedouros e cochos cobertos, com dimensões de 2,00x0,70m. A forragem ingerida pelos animais foi avaliada por intermédio da simulação manual de pastejo. 
O óxido crômico foi administrado via oral a cada animal em dose única diária de $20 \mathrm{~g}$, durante os cinco dias de adaptação e os três dias de coletas de fezes, sempre às $12 \mathrm{~h}$.

A excreção fecal foi estimada utilizando-se o óxido crômico (Burns et al., 1994), sendo calculada com base na razão entre a quantidade do indicador fornecido e sua concentração nas fezes. As estimativas do consumo voluntário individual foram obtidas empregando-se como indicador interno a fibra em detergente ácido indigestível (FDAi).

Após as coletas, as amostras de pasto e fezes foram pré-secas em estufa de ventilação forçada a aproximadamente $60^{\circ} \mathrm{C}$ por $72 \mathrm{~h}$ e, posteriormente, moídas em moinho de faca com peneira com malha de $1 \mathrm{~mm}$. As análises laboratoriais das amostras do pasto e das fezes foram realizadas de acordo com as técnicas descritas por Silva e Queiroz (2002), com exceção das determinações de FDN e FDA, que seguiram os métodos de Mertens (2002) e Van Soest et al. (1991), respectivamente. Na Tab. 2 é apresentada a composição química do pasto e dos suplementos. A quantificação dos carboidratos não fibrosos (CNF) foi feita de acordo com a adaptação de Hall (2000), sendo $\mathrm{CNF}=100-[(\% \mathrm{~PB}-\% \mathrm{~PB}$ derivada da ureia + $\%$ da ureia $)+\%$ FDN $+\%$ EE $+\%$ cinzas $]$.

Tabela 2. Composição química e bromatológica da Brachiaria decumbens e dos suplementos

\begin{tabular}{lcccc} 
& & \multicolumn{3}{c}{ Suplemento } \\
\cline { 3 - 5 } Item & Brachiaria decumbens & 1 & 2 & 3 \\
\hline Matéria seca Matéria orgânica $^{1}$ & 29,14 & 89,66 & 89,29 & 89,16 \\
Proteína bruta $^{1}$ & 92,09 & 92,36 & 93,63 & 94,73 \\
NIDN/N & 8,66 & 31,00 & 31,47 & 31,60 \\
NIDA/N & 26,51 & 7,22 & 7,49 & 7,59 \\
Extrato etéreo $^{1}$ & 21,30 & 3,15 & 3,26 & 3,30 \\
Fibra em detergente neutro $^{1}$ & 2,30 & 2,92 & 3,05 & 3,09 \\
Carboidratos não fibrosos $^{1}$ & 73,60 & 17,40 & 19,09 & 19,25 \\
Lignina $^{1}$ & 7,52 & 49,88 & 48,86 & 49,63 \\
Fibra em detergente ácido indigestível $^{1}$ & 5,88 & 1,52 & 1,56 & 1,57 \\
\hline
\end{tabular}

$1 \%$ MS. NIDN/N $=\%$ nitrogênio insolúvel em detergente neutro no nitrogênio total; NIDA/N = \% nitrogênio insolúvel em detergente ácido no nitrogênio total.

A densidade energética das dietas experimentais, expressa em termos de nutrientes digestíveis totais, foi calculada a partir da fórmula recomendada pelo Nutrient... (2001): NDT $(\%)=$ $\mathrm{PBD}+2,25^{*} \mathrm{EED}+\mathrm{CNFD}+\mathrm{FDND}$, sendo que PBD, EED, CNFD e FDND significam, respectivamente, proteína bruta digestível, extrato etéreo digestível, carboidratos não fibrosos digestíveis e fibra em detergente neutro digestível. A concentração de energia digestível (ED) das dietas foi obtida por intermédio da equação proposta pelo Nutrient... (2001): ED $(\mathrm{Mcal} / \mathrm{kg} \mathrm{MS})=5,6 \times \mathrm{PBD}+9,4 \times \mathrm{EED}+4,2 \times$ FDND + 4,2 x CNFD. Já as concentrações de energia metabolizável (EM) foram consideradas como sendo $82 \%$ da ED (Nutrient..., 2000).

Os animais foram pesados no início e ao final do período experimental, quando foram abatidos, após 16h de jejum, seguindo-se as normas da Portaria 304 do Ministério da Agricultura.
Para obtenção do peso de corpo vazio inicial dos animais que permaneceram no experimento, utilizou-se a relação PCVZ/PC média dos animais do grupo-referência.

Após resfriadas, as carcaças foram novamente pesadas e, na meia carcaça esquerda, mediu-se o comprimento, a espessura de gordura e a área de olho de lombo na altura da $12^{\mathrm{a}}$ costela.

A comparação entre os tratamentos para as variáveis de desempenho e características de carcaça foi realizada por intermédio de contrastes não ortogonais. Os contrastes estabelecidos foram: controle versus suplementados; e os efeitos de ordem linear e quadrática. Para os procedimentos estatísticos utilizou-se o Statistical... (1997) e adotou-se $\alpha=0,10$.

A estimativa da energia corporal foi obtida a partir dos teores corporais de proteína e gordura 
e seus respectivos equivalentes calóricos, conforme a equação preconizada pelo Nutrient... (1980):

$$
C E=5,6405 X+9,3929 Y \text {, }
$$

em que: $\mathrm{CE}=$ conteúdo energético (Mcal); $\mathrm{X}=$ proteína corporal $(\mathrm{kg}) ; \mathrm{Y}=$ gordura corporal $(\mathrm{kg})$.

Os conteúdos de energia e proteína retidos no corpo dos animais foram estimados segundo o modelo:

$$
\mathrm{Y}=\mathrm{a} \cdot \mathrm{X}^{\mathrm{b}}
$$

em que: $\mathrm{Y}=$ conteúdo total de energia (Mcal) ou de proteína $(\mathrm{kg})$ retido no corpo vazio; $\mathrm{a}=$ constante; $\mathrm{b}=$ coeficiente de regressão do conteúdo de energia ou de proteína, em função do PCVZ; $\mathrm{X}=\mathrm{PCVZ}$

Derivando-se as equações de predição do conteúdo corporal de energia ou de proteína, em função do PCVZ, foram obtidas as exigências líquidas de energia e proteína, por $\mathrm{kg}$ de ganho de PCVZ, a partir da equação:

$$
\mathrm{Y}^{\prime}=\mathrm{a} * \mathrm{~b}^{*} \mathrm{X}^{\mathrm{b}-1}
$$

em que: $\mathrm{Y}^{\prime}=$ exigências líquidas de energia ou de proteína para ganho; $\mathrm{a}$ e $\mathrm{b}=$ intercepto $\mathrm{e}$ coeficiente de regressão, respectivamente, das equações de predição dos conteúdos corporais de energia e proteína; e X = PCVZ $(\mathrm{kg})$.

Para conversão do PC em PCVZ, dentro dos intervalos de pesos, calcularam-se as relações entre o PCVZ e o PC dos animais suplementados mantidos no experimento.

O requerimento de energia líquida para mantença (ELm) foi estimado por meio da equação de regressão não linear entre a produção de calor (Y) e o consumo de energia metabolizável
(CEM) dos animais do grupo-mantença e daqueles suplementados segundo Ferrel e Jenkins (1998a,b), de acordo com o modelo $\mathrm{Y}=\mathrm{a} . \mathrm{e}^{\mathrm{b} . \mathrm{CEM}}$, sendo $\mathrm{Y}$ a produção de calor e CEM o consumo de energia metabolizável.

As exigências de energia metabolizável para mantença foram estimadas a partir da relação entre a energia retida (ER, $\mathrm{Mcal} / \mathrm{kg} \mathrm{PCVZ}^{0,75}$ ) e o consumo de energia metabolizável (CEM, $\mathrm{Mcal} / \mathrm{kg} \mathrm{PCVZ}^{0,75}$ ), segundo o modelo: ER $\left(\mathrm{Mcal} / \mathrm{kg} \quad \mathrm{PCVZ}^{0,75}\right)=\beta 1 \quad \mathrm{x}$ CEM $(\mathrm{Mcal} / \mathrm{kg}$ $\left.\mathrm{PCVZ}^{0,75}\right)+\beta 0$, em que $\beta 1$ representa a eficiência de uso da energia metabolizável para ganho de peso. Igualando-se a ER a 0 na equação acima e dividindo-se $\beta_{0} / \beta_{1}$, obtiveram-se as exigências de energia metabolizável para mantença $\left(\mathrm{EM}_{\mathrm{m}}\right)$. A eficiência de uso da energia metabolizável para mantença $\left(\mathrm{K}_{\mathrm{m}}\right)$ foi obtida a partir da razão $\mathrm{EL}_{\mathrm{m}} / \mathrm{EM}_{\mathrm{m}}$.

\section{RESULTADOS E DISCUSSÃO}

Foi observado efeito da suplementação sobre todas as variáveis de desempenho analisadas (Tab. 3). Aumento linear foi verificado para o CMS, enquanto para o consumo de NDT verificou-se comportamento quadrático, com consumo máximo de $5,15 \mathrm{~kg}$ de NDT estimado para um fornecimento de suplemento de $2,88 \mathrm{~kg} /$ dia. Comportamento quadrático também foi observado para o ganho médio diário, que teve uma resposta máxima de $0,91 \mathrm{~kg} /$ dia para um consumo de suplemento de $2,69 \mathrm{~kg} /$ dia. O consumo de energia digestível e o consumo de energia metabolizável apresentaram aumento linear com o aumento da quantidade de suplemento fornecida (Tab. 3).

Tabela 3. Consumo de matéria seca, energia e ganho médio diário de bovinos que receberam diferentes quantidades de suplemento

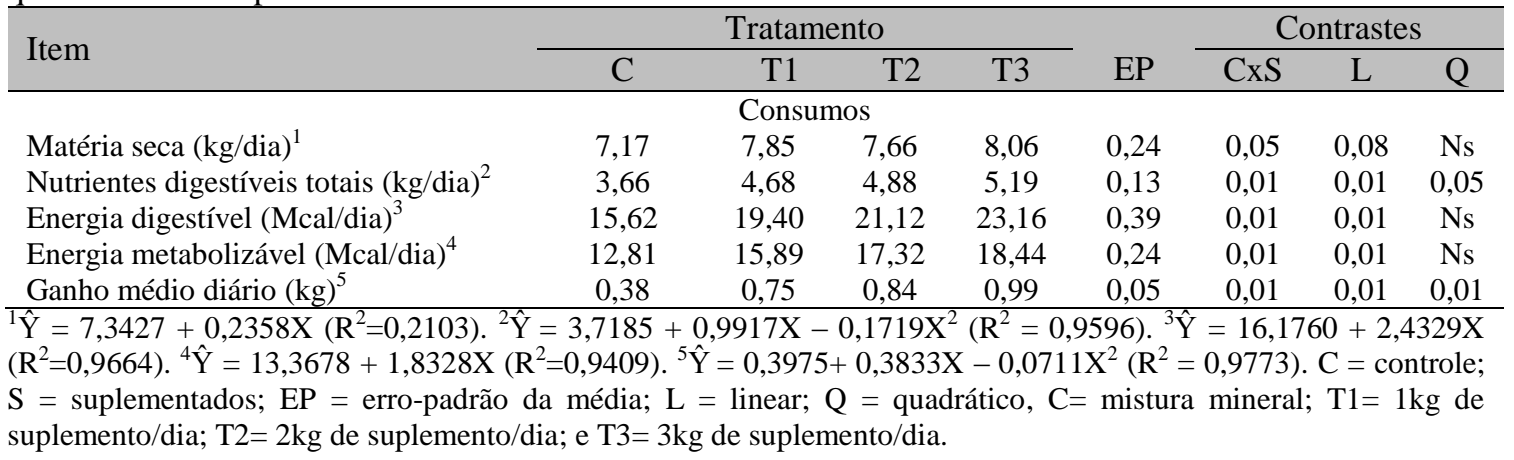


Waldo (1986) afirmou que a suplementação de forragem com concentrado geralmente amplia o consumo total de MS, mas decresce o consumo de forragem. Segundo o Nutrient... (2000), quando mais de $1,0 \mathrm{~kg}$ de suplemento é fornecido diariamente ao animal, a ingestão de forragem pode ser reduzida por substituição. A presença do efeito substitutivo parece ser mais marcante no uso de suplementos de natureza energética (Minson, 1990; Poppi e McLennan, 1995). Tal fato pode ter provocado efeito quadrático para o consumo de NDT e, consequentemente, para o ganho médio diário.

Verificou-se efeito linear da suplementação sobre o peso corporal em jejum, o peso de corpo vazio e o peso da carcaça quente (Tab.4). Não foi observado efeito dos níveis de suplemento sobre o rendimento da carcaça, tanto em relação ao peso corporal quanto em relação ao peso de corpo vazio (Tab. 4).

Freitas et al. (2008), trabalhando com bovinos Nelore não castrados e castrados, em confinamento, recebendo dietas com $12 \%$ de PB e 2,9Mcal de ED/kg de MS, observaram pesos médios de carcaça quente de $214,89 \mathrm{~kg}$ para os animais inteiros, com rendimentos de carcaça de $53,71 \%$. O peso de carcaça quente observado pelos autores foi superior aos pesos encontrados neste estudo, uma vez que os animais foram terminados em confinamento. No entanto, o rendimento de carcaça relatado por esses autores foi inferior aos observados para todos os tratamentos avaliados neste estudo.

Não foi verificado efeito da suplementação, bem como dos níveis de suplemento sobre os rendimentos dos cortes comerciais da carcaça (Tab.4). Avaliando níveis de suplementação (1 e $2 \mathrm{~kg} / \mathrm{dia})$, Zervoudakis et al. (2001) também não observaram diferença quanto ao rendimento dos cortes básicos da carcaça nem quanto aos rendimentos dos quartos traseiro e dianteiro entre os animais submetidos aos diferentes suplementos. Estes resultados evidenciam uma tendência de manutenção do equilíbrio entre os quartos traseiro e dianteiro, independentemente do peso de abate e do nível nutricional imposto aos animais (Berg e Buterfield, 1976).

Verificou-se efeito da suplementação sobre a área de olho de lombo e a espessura de gordura subcutânea, o que não ocorreu com relação ao comprimento da carcaça (Tab. 4).

Não foram observados efeitos dos níveis de suplementação sobre a área de olho de lombo, a espessura de gordura subcutânea e o comprimento da carcaça. A falta de efeito das quantidades de suplemento sobre a espessura de gordura subcutânea pode indicar ausência de diferenças quanto à maturidade fisiológica (terminação) entre os animais suplementados, e o baixo valor da espessura de gordura subcutânea deve ser consequência do baixo peso corporal final dos animais desse experimento ou ainda de insuficiência do consumo de energia metabolizável proporcionado pelos tratamentos, para que houvesse sobra de energia, para deposição de gordura, além daquela demandada para deposição de músculo.

Zervoudakis et al. (2001), avaliando o efeito da suplementação sobre essas mesmas características da carcaça, não observaram diferença entre os animais submetidos aos diferentes suplementos, encontrando valor médio de 7,45mm de espessura de gordura subcutânea. No entanto, este valor foi encontrado para bovinos castrados e ainda com idade e pesos mais elevados, justificando o valor bem superior ao encontrado neste estudo.

Com relação à área de olho de lombo, os valores médios foram superiores para os animais suplementados e apresentaram-se inferiores aos encontrados por Zervoudakis et al. (2001), que variaram de 79,3 a $91,8 \mathrm{~cm}^{2}$.

Comparando-se os animais do tratamentocontrole com os animais suplementados, foram verificadas maiores porcentagens de músculo, gordura e EE na carcaça dos suplementados (Tab. 5). Não foi verificado, entretanto, efeito da suplementação sobre nenhum dos itens quando se analisaram as quantidades de suplemento.

O valor médio obtido neste estudo para o teor de gordura na carcaça com o fornecimento de suplemento, de 16,3\%, mostrou-se aquém do relatado em animais confinados (Paulino et al., 2004). As carcaças de todos os animais utilizados neste estudo eram escassas em gordura, e este comportamento reflete, possivelmente, o fato de estes animais terem sido abatidos com baixo peso corporal. 
Tabela 4. Pesos e características da carcaça de bovinos que receberam diferentes quantidades de suplemento

\begin{tabular}{|c|c|c|c|c|c|c|c|c|}
\hline \multirow[b]{2}{*}{ Item } & \multicolumn{4}{|c|}{ Tratamento } & \multirow[b]{2}{*}{ EP } & \multicolumn{3}{|c|}{ Contrastes } \\
\hline & $\mathrm{C}$ & $\mathrm{T} 1$ & T2 & T3 & & $\mathrm{CxS}$ & $\mathrm{L}$ & $\mathrm{Q}$ \\
\hline \multicolumn{9}{|c|}{ Peso $(\mathrm{kg})$} \\
\hline Corporal em jejum & 325,16 & 328,83 & 339,16 & 361,00 & 5,46 & 0,01 & 0,05 & ns \\
\hline Corporal vazio & 296,23 & 303,11 & 314,75 & 327,03 & 4,75 & 0,03 & 0,06 & ns \\
\hline Carcaça quente & 180,90 & 189,25 & 197,26 & 201,75 & 1,48 & 0,05 & 0,08 & ns \\
\hline \multicolumn{9}{|c|}{ Rendimento (\%) } \\
\hline Carcaça/peso corporal & 55,64 & 57,69 & 58,13 & 55,88 & 1,91 & ns & ns & ns \\
\hline Carcaça/peso corporal vazio & 61,10 & 62,45 & 62,66 & 61,67 & 3,27 & ns & ns & ns \\
\hline Paleta & 17,57 & 17,41 & 18,00 & 18,11 & 0,33 & ns & ns & ns \\
\hline Acém & 23,96 & 23,31 & 21,92 & 22,22 & 0,49 & ns & ns & ns \\
\hline Dianteiro & 41,54 & 40,72 & 39,92 & 40,33 & 0,29 & ns & ns & ns \\
\hline Coxão & 28,74 & 28,87 & 29,81 & 30,16 & 0,30 & ns & ns & ns \\
\hline Alcatra & 18,79 & 18,83 & 19,03 & 19,08 & 0,21 & ns & ns & ns \\
\hline Ponta de agulha & 10,86 & 10,91 & 11,01 & 11,31 & 0,21 & ns & ns & ns \\
\hline Traseiro & 58,45 & 59,27 & 59,66 & 60,07 & 0,29 & ns & ns & ns \\
\hline \multicolumn{9}{|c|}{ Característica da carcaça } \\
\hline Área de olho de lombo ${ }^{1}$ & 54,00 & 55,88 & 56,57 & 60,72 & 1,07 & 0,02 & ns & ns \\
\hline $\begin{array}{l}\text { Espessura de gordura } \\
\text { subcutânea }^{2}\end{array}$ & 1,70 & 1,83 & 1,83 & 1,96 & 0,11 & 0,01 & ns & ns \\
\hline Comprimento da carcaça ${ }^{3}$ & 107,33 & 108,00 & 109,00 & 111,00 & 1,03 & ns & ns & ns \\
\hline
\end{tabular}

${ }^{1} / \mathrm{cm}^{2} .{ }^{2} / \mathrm{mm} .{ }^{3} / \mathrm{cm}$. C $=$ mistura mineral; $\mathrm{T} 1=1 \mathrm{~kg}$ de suplemento $/ \mathrm{dia} ; \mathrm{T} 2=2 \mathrm{~kg}$ de suplemento $/$ dia; e $\mathrm{T} 3=3 \mathrm{~kg}$ de suplemento/dia.

Tabela 5. Composição física e química da carcaça de bovinos recebendo diferentes quantidades de suplemento

\begin{tabular}{|c|c|c|c|c|c|c|c|c|}
\hline \multirow[b]{2}{*}{ Item } & \multicolumn{4}{|c|}{ Tratamento } & \multirow[b]{2}{*}{ EP } & \multicolumn{3}{|c|}{ Contrastes } \\
\hline & $\mathrm{C}$ & $\mathrm{T} 1$ & $\mathrm{~T} 2$ & T3 & & $\mathrm{CxS}$ & $\mathrm{L}$ & Q \\
\hline \multicolumn{9}{|c|}{ Composição física } \\
\hline Músculo & 62,23 & 64,33 & 63,63 & 63,33 & 0,75 & 0,08 & ns & ns \\
\hline Gordura & 15,00 & 16,30 & 16,33 & 16,33 & 0,73 & 0,05 & ns & ns \\
\hline Osso & 22,63 & 19,73 & 20,26 & 20,43 & 0,38 & ns & ns & ns \\
\hline \multicolumn{9}{|c|}{ Composição química } \\
\hline Proteína bruta & 19,79 & 19,14 & 17,43 & 18,23 & 0,41 & ns & ns & ns \\
\hline Extrato etéreo & 10,38 & 12,31 & 12,32 & 13,42 & 0,50 & 0,03 & ns & ns \\
\hline Matéria mineral & 7,69 & 7,26 & 7,01 & 7,02 & 0,26 & ns & ns & $\mathrm{ns}$ \\
\hline Água & 62,11 & 61,29 & 63,24 & 61,33 & 0,56 & ns & ns & $\mathrm{ns}$ \\
\hline
\end{tabular}

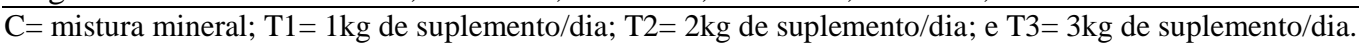

A relação obtida para a estimativa do peso de corpo vazio (PCVZ) a partir do peso corporal (PC) dos animais foi: $\mathrm{PCVZ}=\mathrm{PC}^{*} 0,9078$. Tal valor encontra-se próximo ao recomendado pelo Nutrient... (2000) de 0,8910 e dos valores de $0,8975, \quad 0,8956$ e 0,8950 observados, respectivamente, por Silva et al. (2002), Paulino et al. (2004) e Valadares Filho et al. (2010), obtidos com animais da raça Nelore em confinamento. Para animais em pasto, a relação recomendada por Valadares Filho et al. (2010) foi de 0,863 .
A relação entre o ganho de peso corporal (GPC) e o ganho de peso de corpo vazio (GPCVZ) foi de 0,9246, ou seja, devem-se multiplicar as exigências fornecidas em função do ganho de peso corporal por 0,9246 para se encontrar as exigências do ganho de peso de corpo vazio. $\mathrm{O}$ Nutrient... (2000) preconizou a relação 0,956 entre o GPCVZ e o GPC, já Valadares Filho et al. (2010) propuseram valor de 0.936 para bovinos Nelore em confinamento, 0,966 para bovinos cruzados em confinamento e 0,955 para animais a pasto. 
Foram geradas, por meio do SAS, equações de regressão dos conteúdos de energia (Mcal) ou de proteína $(\mathrm{kg})$ em função do peso de corpo vazio (kg), usando-se os dados dos animais-referência, tratamento-controle e suplementados (Tab. 6).

Tabela 6. Parâmetros da regressão para os conteúdos de energia e proteína no corpo vazio de bovinos de corte a pasto

\begin{tabular}{lccc}
\hline Itens & Intercepto & Coeficiente & $\mathrm{r}^{2}$ \\
\hline Energia & 0,0737 & 1,5926 & 0,92 \\
Proteína & 1,4916 & 0,6387 & 0,82 \\
\hline
\end{tabular}

Segundo Berg e Butterfield (1976), à medida que o peso corporal se eleva, a concentração de gordura no corpo aumenta, com consequente aumento nas exigências energéticas, uma vez que há aumento no valor energético do ganho, juntamente com aumento no peso dos animais. Da mesma forma, Backes et al. (2005) observaram que tanto os zebuínos quanto os seus mestiços apresentaram exigências de proteína numericamente superiores na fase de recria em relação à de terminação, confirmando o fato de que, à medida que se eleva o peso corporal, as exigências de proteína decrescem, em decorrência da queda no desenvolvimento muscular.

Neste estudo, para um bovino com $350 \mathrm{~kg}$ de peso corporal e ganho de peso de corpo vazio de 1,0kg/dia, as exigências líquidas de energia e proteína foram estimadas em 3,57 Mcal e $118,79 \mathrm{~g}$, respectivamente (Tab. 7).

Tabela 7. Exigências líquidas de energia e proteína de bovinos de corte sob pastejo

\begin{tabular}{ccc}
$\begin{array}{l}\text { Peso corporal } \\
(\mathrm{kg})\end{array}$ & Exigências de energia (Mcal/kg GPCVZ) & $\begin{array}{l}\text { Exigências de proteína }(\mathrm{g} / \mathrm{kg} \\
\text { GPCVZ) }\end{array}$ \\
\hline 300 & 3,26 & 125,60 \\
350 & 3,57 & 118,79 \\
\hline
\end{tabular}

$\mathrm{PCVZ}=\mathrm{PV} * 0,9078 . \mathrm{PCVZ}=$ peso de corpo vazio; $\mathrm{PV}=$ peso vivo ou peso corporal.

Por meio da compilação de dados de exigências nutricionais de bovinos de corte no Brasil, Valadares Filho et al. (2010) estimaram as exigências líquidas de proteína para ganho de peso de bovinos zebu não castrados, com $350 \mathrm{~kg}$, em $164,78 \mathrm{~g} / \mathrm{dia}$.
As exigências líquidas de energia para mantença (ELm) foram estimadas a partir da relação exponencial entre a produção de calor (PC, $\mathrm{Mcal} / \mathrm{kg} \mathrm{PCVZ}^{0,75}$ ) e o consumo de energia metabolizável (CEM, Mcal/kg PCVZ ${ }^{0,75}$ ) (Fig. 1), conforme preconizado por Ferrell e Jenkins (1998a,b).

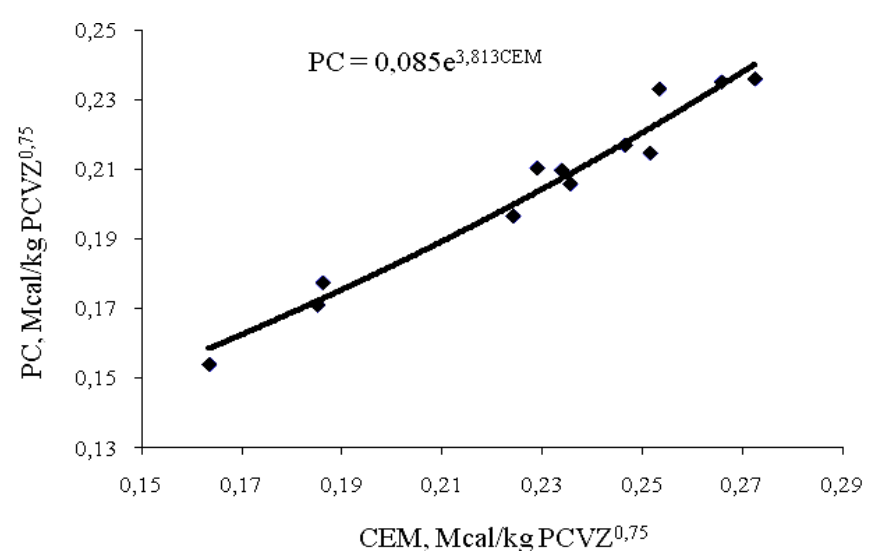

Figura 1. Relação entre produção de calor (PC) e consumo de energia metabolizável (CEM) em bovinos sob pastejo. 
A equação foi traçada com os dados de todos os animais do experimento, sendo a estimativa da $\mathrm{ELm}$ de $85 \mathrm{kcal} / \mathrm{kg} \mathrm{PCVZ}^{0,75}$. Este valor foi superior àqueles encontrados por Moraes (2006) e Paixão (2008), de 69,33 e 74,01kcal $/ \mathrm{kg}$ $\mathrm{PCVZ}^{0,75}$, respectivamente, os quais trabalharam com animais em condições semelhantes às deste estudo.

Conforme salientado anteriormente, animais em pastejo podem apresentar requisitos de energia para mantença maior do que aqueles criados em confinamento, em razão da maior atividade física que exercem. Osuji (1974) observou que a atividade de pastejo pode aumentar os requerimentos de energia de ruminantes de 25 a $50 \%$ em comparação aos animais em confinamento e que considerável parte deste aumento pode ser atribuído ao gasto energético para locomoção e colheita de forragem.

O requisito de energia metabolizável para mantença tem sido definido como sendo o consumo de energia metabolizável (CEM) por dia, em que o balanço energético do animal torna-se nulo (Dawson e Steen, 1998). A equação obtida foi: $\mathrm{ER}=0,246$ x $\mathrm{CEM}-0,032$ (Fig. 2). De acordo com essa equação, as exigências de energia metabolizável para mantença de bovinos Nelore a pasto seriam de $130,08 \mathrm{kcal} / \mathrm{kg} \mathrm{PCVZ}{ }^{0,75}$, com uma eficiência de utilização da energia metabolizável para ganho $\left(\mathrm{k}_{\mathrm{g}}\right)$ de $24,6 \%$. Dividindo-se as exigências de $\operatorname{EL}_{\mathrm{m}}(85,0)$ pelas exigências de $\operatorname{EM}_{\mathrm{m}}(130,1)$, obteve-se o valor da eficiência de uso da energia metabolizável para mantença $\left(\mathrm{k}_{\mathrm{m}}\right)$ de $64,2 \%$.

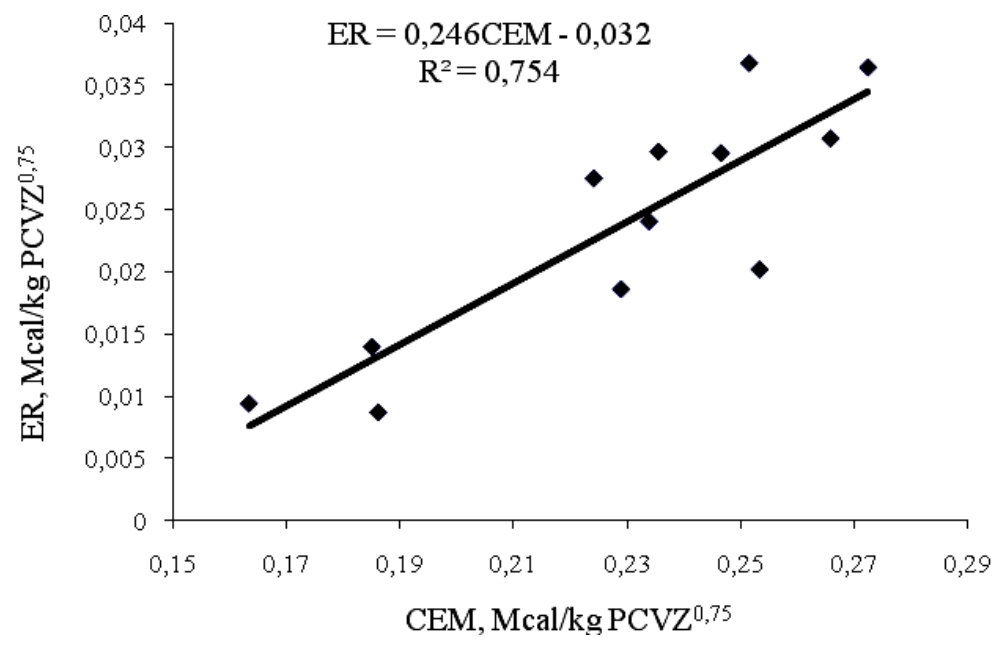

Figura 2 . Relação entre energia retida (ER) e consumo de energia metabolizável em bovinos a pasto.

Valadares Filho et al. (2010) obtiveram, para animais confinados, valor de $112,4 \mathrm{kcal} / \mathrm{PCVZ}^{0,75}$ para as exigências de energia metabolizável de mantença, e para animais em pastejo, 124,7 $\mathrm{kcal} / \mathrm{PCVZ}^{0,75} /$ dia. Observa-se que a exigência de mantença obtida nessa pesquisa foi $4,3 \%$ maior que o valor obtido para animais em pastejo recomendado por Valadares Filho et al. (2010). Com relação aos animais confinados, o aumento nos requisitos de EMm foi de $15,7 \%$. O valor obtido neste estudo mostrou-se mais elevado que o sugerido pelo NRC (2000). Todavia, revisando dados disponíveis na literatura, o CSIRO (1990) estimou aumentos no requisito de energia para mantença de até $50 \%$ para animais a pasto percorrendo grandes distâncias de declividade acentuada, para exercer a seletividade.

\section{CONCLUSÕES}

A suplementação de bovinos no período de transição águas-seca aumenta o consumo de matéria seca e de energia, promovendo, em consequência, aumento do ganho de peso dos animais. $\mathrm{O}$ consumo de suplemento influencia as principais características da carcaça, no entanto não interfere no rendimento dos cortes nem da carcaça como um todo. 


\section{REFERÊNCIAS}

BACKES, A.A.; PAULINO, M.F.; ALVES, D.D. et al. Composição corporal e exigências energéticas e proteicas de bovinos mestiços leiteiros e zebu, castrados, em regime de recria e engorda. Rev. Bras. Zootec., v.34, p.257-267, 2005.

BARBOSA, F.A.; GRAÇA, D.S.; MAFFEI, W.E. et al. Desempenho e consumo de matéria seca de bovinos sob suplementação proteicoenergética durante a época de transição águaseca. Arq. Bras. Med. Vet. Zootec., v.59, p.160167, 2007.

BERG, R.T.; BUTTERFIELD, R.M. New concepts of cattle growth. New York: Sydney University, 1976. 240p.

BURNS, J.C.; POND, K.R.; FISHER, D.S. Measurament of forage intake. In: FAHEY JUNIOR, G.C. Forage quality, evaluation and utilization. Madison: America Society of Agronomy, 1994. p.494-531.

CSIRO. Feeding standards for Australian livestock. Ruminants. Melbourne: Print Advisory Service Melbourne, 1990, 266p.

DAWSON, L.E.R.; STEEN, R.W.J. Estimation of maintenance energy requirements of beef cattle and sheep. J. Agric. Sci., v.131, p.477-485, 1998.

FERRELL, C.L.; JENKINS, T.G. Body composition and energy utilization by steers of diverse genotypes fed a high-concentrate diet during the finishing period: I. Angus, Belgian Blue, Hereford, and Piedmontese sires. J. Anim. Sci., v.76, p.637-646, 1998a.

FERRELL, C.L.; JENKINS, T.G. Body composition and energy utilization by steers of diverse genotypes fed a high-concentrate diet during the finishing period: II. Angus, Boran, Brahman, Hereford, and Tuli sires. J. Anim. Sci., v.76, p.647-657, 1998b.

FREITAS, A.K.; RESTLE, J.; PACHECO, P.S. et al. Características de carcaça de bovinos Nelore inteiros vs castrados em duas idades, terminados em confinamento. Rev. Bras. Zootec, v.37, p.1055-1062, 2008.

HALL, M.B. Calculation of non-structural carbohydrate content of feeds that contain noprotein nitrogen. (Bulletin 339, p.A-25, 2000).
MERTENS, D.R. Gravimetric determination of amylase treated neutral detergent fiber in feeds with refluxing in beakers or crucibles: Collaborative study. J. AOAC Intern., v.85, p.1212-1240, 2002.

MINSON, D.J. Forage in ruminant nutrition. San Diego: Academic Press, 1990. 483p.

MORAES, E.H.B.K. Desempenho e exigências de energia, proteína e minerais de bovinos de corte em pastejo, submetidos a diferentes estratégias de suplementação. 2006. 172f. Tese (Doutorado em Zootecnia) - Universidade Federal de Viçosa, Viçosa, MG.

NUTRIENT requirements of beef cattle. 7.ed. Washington: National Academy of Sciences 2000. 242p.

NUTRIENT requirements of dairy cattle. 7.ed. Washington: National Academy of Sciences, 2001. 381p.

OSUJI, P.O. The physiology of eating and the energy expenditure of the ruminant at pasture. $J$. Rang. Manag., v.27, p.437-443, 1974.

PAIXÃO, M.L. Desempenho produtivo $e$ exigências nutricionais de bovinos de corte em pastagens de Brachiaria decumbens, com suplementação proteica. 2008. 124f. Tese (Doutorado em Zootecnia) - Universidade Federal de Viçosa, Viçosa, MG.

PAULINO, P.V.R.; COSTA, M.A.L.; VALADARES FILHO, S.C. et al. Exigências nutricionais de zebuínos: Energia. Rev. Bras. Zootec., v.33, p.781-791, 2004.

POPPI, D.P.; McLENNAN, S.R. Protein and energy utilization by ruminants at pasture. $J$. Anim. Sci., v.73, p.278-290, 1995.

REIS, R.A.; RODRIGUES, L.R.A; PEREIRA, J.R.A. Suplementação como estratégia de manejo de pastagem. In: SIMPÓSIO SOBRE MANEJO DE PASTAGEM, 13., 1997, Piracicaba. Anais...Piracicaba: FEALQ. 1997. P.123-150.

SILVA, D.J.; QUEIROZ, A.C. Análise de Alimentos: métodos químicos e biológicos. 3.ed. Viçosa: UFV, 2002. 235p. 
SILVA, F.F.; VALADARES FILHO, S.C.; ÍTAVO, L.C.V. et al. Composição corporal e requisitos energéticos e proteicos de bovinos nelore, não-castrados, alimentados com rações contendo diferentes níveis de concentrado e proteína. Rev. Bras. Zootec., v.31, p.503-513, 2002.

STATISTICAL Analysis System Institute - SAS - Institute SAS/STAT software: changes and enhancements through release 6.12. Cary, 1997. $1167 \mathrm{p}$.

VALADARES FILHO, S.C.; MARCONDES, M.I.; CHIZZOTTI, M.L.; PAULINO, P.V.R. Exigências nutricionais de zebuínos puros $e$ cruzados - BR CORTE. 2.d. Viçosa:UFV, 2010. $193 \mathrm{p}$.
VAN SOEST, P.J.; ROBERTSON, J.B.; LEWIS, B.A. Methods for dietary fiber, neutral detergent fiber, and nonstarch polyssacarides in relation to animal nutrition. J. Anim. Sci, v.74, p.3583-3597, 1991.

WALDO, D.R. Symposium: forage utilization by the lactating cow. Effect of forage quality on intake and forage concentrate interactions. $J$. Dairy Sci., v.69, p.617-631, 1986.

ZERVOUDAKIS, J.T.; PAULINO, M.F.; DETMANN, E. et al. Desempenho e características de carcaça de novilhos suplementados no período das águas. Rev. Bras. Zootec, v.34, p.1381-1389, 2001. 